\title{
Ayurveda for hypertriglyceridemia: a case report
}

\begin{abstract}
Background: Cardiovascular disease is one of the major concerns in medical fraternity today and dyslipidemia has been found to be an important associating factor. With the inclination of world towards herbal treatments as a promising tool to combat dyslipidemia, Ayurveda proves to be a time tested formula with research studies acknowledging its efficacy. To be more specific with the treatment protocols, efficacy of Ayurveda medicines in treating hyper-triglyceridemia has been evaluated in current case report.
\end{abstract}

Clinical features: Patient with age 50yrs, male, working as an accountant with private firm, was diagnosed with hyper-cholesterolmia about 3-4 years before presenting himself for Ayurveda treatment. He had not responded convincingly to earlier conventional treatment and his increased triglycerides levels failed to decrease although total cholesterol had declined.

Intervention and Outcome: Patient was treated for about six months with Ayurveda formulae Phalatrikadi guggul, Arogyavardhini Vati and Trifala tablet. Lipid profile levels were tested using venous blood sample obtained after 12 hours of fasting and plasma concentration of triglycerides was assessed by spectrophotometry method, enzymatic endpoint. After the said treatment, triglycerides dropped from $187 \mathrm{mg} / \mathrm{dl}$ at beginning of treatment to $150 \mathrm{mg} / \mathrm{dl}$ after two months of treatment and further dropped down to $130 \mathrm{mg} / \mathrm{dl}$ even after tapering dose and remained stable between $130-150 \mathrm{mg} /$ $\mathrm{dl}$ even without medication over next six months.

Conclusion: This case report can be used as a pointer to state that Ayurveda treatment can be an effective tool for reduction of hyper-triglyceridemia. Further standardized trials are required on larger scale to demonstrate its efficacy and understand the mechanism.

Keywords: ayurveda, hypertriglyceridemia, arogyavardhini, phalatrikadi guggulu
Volume 5 Issue 5 - 2018

\author{
Barve Vaibhavi Shridhar \\ Ayurveda clinic in Goa, India
}

Correspondence: Barve Vaibhavi Shridhar, ayurveda clinic in Goa, India, Tel +91 8975179559, Email barvevaibhavi@rediffmail. com

Received:June 18,2018 | Published: September 10, 2018
Abbreviations: TGL,Triglycerides; LDL, Low Density Lipoproteins; HDL, High Density Lipoproteins

\section{Introduction}

Ayurveda has been practiced in India for about last 5000 yrs. Aim of Ayurveda is to balance the five elements in body through diet, herbs, cleansing procedures and Yoga. Thus, it acts at mental as well as physical level. Hyperlipidemia has been recognized as an impending risk factor for diseases like the metabolic syndrome, cardiovascular diseases, and hypertension. It has been defined as the presence of raised or abnormal levels of lipids and/or lipoproteins in the blood. ${ }^{1}$ globally, raised cholesterol is estimated to be responsible for $18 \%$ of cerebrovascular disease and $56 \%$ of ischemic heart disease. Overall, these diseases accounts for about 4.4 million deaths (7.9\% of the total) and 40.4 million disability adjusted life years (DALYs) $(2.8 \%$ of the total. ${ }^{2}$ With advent of newer dimensions in medical field, a need for safe and effective treatment options is on rise.

\section{Case presentation}

Patient with age 50yrs, male, working as an accountant with private firm, was diagnosed with hypercholesterolemia about 3-4 years before presenting himself for Ayurveda treatment. He had not responded convincingly to earlier conventional treatment and his triglycerides levels failed to decrease although total cholesterol had declined. Symptoms included dyspnea on exertion, fatigue, occasional neck pain due to office workload. Bowel habits were irregular and had frequent constipation; pulse and blood pressure were within normal standard limits. No history of diabetes mellitus and no significant ailment history reported.

\section{Intervention and outcome}

Arogyavardhini Vati is a polyherbal formulation mentioned in Ayurvedic formulary. ${ }^{3}$ It consists of Terminalia chebula (Haritaki), Terminalia bellerica (Bibhitaka), Emblica officinalis (Amalaki), Asphaltum (Silajatu-Suddha), Commiphora wightii (Guggulu Shuddha), Ricinus communis (Eranda), Picrorrhiza kurroa (Katuka), leaf juice of Azadirachta indica (Nimba) and metals including Shuddha Rasa (purified mercury), Shuddha Gandhaka (purified sulfur), Lauha Bhasma (iron compound in ash form), Abhraka Bhasma (mica in ash form), and Tamra Bhasma (copper compounds in ash form). In patients with coronary heart disease, a randomized controlled trial of Terminalia arjuna and arogyavardhini demonstrated significant decrease in total cholesterol and LDL cholesterol and also significant decrease in lipid peroxide, ${ }^{4}$ Safety of Arogyavardhini Vati on liver, kidney, and brain has been evaluated in earlier studies. ${ }^{5}$

Arogyavardhini was given as $250 \mathrm{mg}$ tablet twice a day after meals. Gurjar et al., ${ }^{6}$ has shown that herbal treatment with trifala significantly improved the lipid profiles of the mice by lowering serum total cholesterol (Total-C), TG, and low-density lipoprotein cholesterol (LDL-C) and increasing levels of high-density lipoprotein cholesterol 
(HDL-C) as compared to the mice in the High Fat Diet group. ${ }^{6}$ Trifala mainly comprises three constituents namely, Terminalia chebula (Haritaki), Terminalia bellerica (Bibhitaka), Emblica officinalis (Amalaki).

Trifala tablet was administered in dose of one tablet of $250 \mathrm{mg}$ bedtime with warm water. Phalatrikadi which contains Amalaki (Emblica officinalis), Bibhitaki (Terminalia bellerica), Haritaki (Terminalia chebula), Guduci (Tinospora cordifolia), Vasa (Adhatoda vasica), Kalmegha(Andrographis panniculata), Nimba (Azadirachta indica), Kutaki(Picrorrhiza kurroa) shows capacity of hepatocellular regeneration, Cholegogue and cholertic activity, Membrane stabilizing effect, Antiviral and antioxidant effect, Molecular nutrient effect, Enzyme and metabolic corrections. ${ }^{7}$ The components of guggulu are known to have hypolipidemic effects. ${ }^{8}$ Hence for potent action phalatrikadi guggul was chosen.

Phalatrikadi guggulu was administered as $500 \mathrm{mg}$ tablets twice a day at $6 \mathrm{am}$ and $6 \mathrm{pm}$. This dosage was continued for upto 2 months and later it was tapered to arogyavardhini $250 \mathrm{mg}$ twice a day after meals, trifala tablet $250 \mathrm{mg}$ bedtime, and phalatrikadi guggulu $250 \mathrm{mg}$ twice a day at $6 \mathrm{am}$ and $6 \mathrm{pm}$ for another 3 months and investigations were repeated at $6^{\text {th }}$ month from baseline. Since variables were within normal range medicine was stopped and investigations were repeated on 10th and 13th month to monitor lipid profiles without any medications. Lipid profiles were done using venous blood samples obtained after 12 hours of fasting. Plasma concentration of triglycerides was thus obtained by spectrophotometry method, enzymatic endpoint Table 1 .

Table I Blood investigation of lipid profile of the patient

\begin{tabular}{lllll}
\hline & $\begin{array}{l}\text { Total cholesterol } \\
\mathbf{m g} / \mathbf{d l}\end{array}$ & $\begin{array}{c}\text { TGL } \\
\mathbf{m g} / \mathbf{d l}\end{array}$ & $\begin{array}{l}\text { LDL } \\
\mathbf{m g} / \mathbf{d l}\end{array}$ & $\begin{array}{l}\text { HDL } \\
\mathbf{m g} / \mathbf{d l}\end{array}$ \\
\hline Baseline & 267 & 187 & 225 & 36 \\
2 months & 187 & 150 & 90 & 38 \\
6 months & 185 & 140 & 106 & 49 \\
10 month & 181 & 130 & 109 & 48 \\
13 month & 178 & 130 & 108 & 49 \\
\hline
\end{tabular}

TGL-triglycerides, LDL-Low density Lipoprotein, HDL-High Density Lipoprotein Normal range for TGL: less than 150 normal, 150-199 borderline high, 200-499 High, more than equal to 500 very high.

\section{Discussion}

Thus, treatment of about 6months showed notable changes in the lipid profiles, specifically in triglyceride levels reducing from $187 \mathrm{mg} /$ $\mathrm{dl}$ at baseline to $140 \mathrm{mg} / \mathrm{dl}$ despite no major changes in diet and lifestyle. Furthermore, lipid profiles remained stable for next 7 months even when medications were completely stopped. Simple herbal formulations helped in correcting the lipid metabolism without any reported adverse effects. Such herbs can become a promising answer in medical field of present era where drug resistance has become an issue of extreme concern. All the formulations used in current case reports have been scientifically studied earlier and are safe for administration under expert guidance.

The mechanisms by which Arogyavardhini Vati exerts the beneficial effects in hypertriglyceridemia are presently not clear. Picrorhiza kurroa, a major component Arogyavardhini Vati, has choleretic effects. ${ }^{9}$ Amla, which is another component, has HMG CoA reductase inhibitory activity. ${ }^{10}$ These inhibitory activities may explain the beneficial effects of Arogyavardhini Vati on lipid parameters. Inflammation is known to reduce HDL levels, and Arogyavardhini Vati has anti-inflammatory activity. Hence, this could be the reason for raised HDL levels. ${ }^{11}$ Management with triphala, an Ayurvedic formulation reversed the pathological changes in liver tissue and decreased the relative weight of visceral adipose fat pads and findings suggest that triphala and its constituents can counter the effects of an environment (i.e. high dietary intake of fats) and can be used potentially as antiobesity agents with desirable lipid-profile modulating properties. ${ }^{6}$ Phalatrikadi guggulu shows capacity of hepato-cellular regeneration, Cholegogue and cholertic activity, Membrane stabilizing effect, Antiviral and antioxidant effect, Molecular nutrient effect, Enzyme and metabolic corrections. ${ }^{7}$ Mechanism of individual drug component may give specific mode of action. No conclusions can be drawn from single case study but it can definitely be a pointer towards efficacy of ayurved medicines for management of lipid disorders. It can be referred as a pilot study for conducting trial of bigger magnitude.

\section{Acknowledgments}

None.

\section{Conflict of interest}

The author declares that there is no conflict interest.

\section{References}

1. Nadkarni MA, Vyas SN, Baghel MS, et al. Randomized placebo-controlled trial of Mustadi Ghanavati in hyperlipidemia. Ayu. 2010;31(3):287-293.

2. World Health Organization. Reducing risks, promoting healthy life. Geneva: The World Health Report. 2002.

3. Anonymous. Ayurvedic Formulary of India. Ministry of Health and Family Welfare, Government of India. 2005.

4. Kumar G, Srivastava A, Sharma SK. et al. Safety and efficacy evaluation of Ayurvedic treatment (Arjuna powder and Arogyavardhini Vati) in dyslipidemia patients: A pilot prospective cohort clinical study. Ayu. 2012;33(2):197-201.

5. Kumar G, Srivastava A, Sharma SK, et al. Safety evaluation of an Ayurvedic medicine,Arogyavardhini Vati on brain, liver and kidney in rats. J Ethnopharmacol. 2012;140(1):151-160.

6. Gurjar S, Pal A, Kapur S. Triphala and its constituents ameliorate visceral adiposity from a high-fat diet in mice with diet-induced obesity. Altern Ther Health Med. 2012;18(6):38-45.

7. Nirmal Kumar. Phalatrikadi kvatha - an ayurvedic hepatoprotective drug. IJRPC; 2013;3(3).

8. Nohr LA, Rasmussen LB, Straand J. Resin from the mukul myrrh tree, guggul, can it be used for treating hypercholesterolemia? A randomized, controlled study. Complement Ther. 2009;17:16-22.

9. Shukla B, Visen PK, Patnaik GK, et al. Choleretic effect of picroliv, the hepatoprotective principle of Picrorhiza kurroa. Planta Med. 1991;57(1):29-33.

10. Anila L, Vijayalakshmi NR. Flavonoids from Emblica officinalis and Mangifera indica-effectiveness for dyslipidemia. J Ethnopharmacol. 2002;7991:81-87.

11. Cabana VG, Siegel JN, Sabesin SM. Effects of the acute phase response on the concentration and density distribution of plasma lipids and apolipoproteins. J Lipid Res. 1989;30(1):39-49. 